University of Nebraska - Lincoln

DigitalCommons@University of Nebraska - Lincoln

Management Department Faculty Publications

Management Department

8-2008

\title{
Supply Chain Risk, Simulation, and Vendor Selection
}

Desheng Wu

RiskChina Research Center and RiskLab, University of Toronto

David L. Olson

University of Nebraska-Lincoln, dolson3@unl.edu

Follow this and additional works at: https://digitalcommons.unl.edu/managementfacpub

Part of the Management Sciences and Quantitative Methods Commons

Wu, Desheng and Olson, David L., "Supply Chain Risk, Simulation, and Vendor Selection" (2008).

Management Department Faculty Publications. 30.

https://digitalcommons.unl.edu/managementfacpub/30

This Article is brought to you for free and open access by the Management Department at DigitalCommons@University of Nebraska - Lincoln. It has been accepted for inclusion in Management Department Faculty Publications by an authorized administrator of DigitalCommons@University of Nebraska - Lincoln. 
Published in International Journal of Production Economics 114:2 (August 2008), pp. 646-655; Special Section on Logistics Management in Fashion Retail Supply Chains; doi 10.1016/j.ijpe.2008.02.013 Copyright @ 2008 Elsevier B.V. Used by permission.

http://www.elsevier.com/locate/ijpe

Submitted October 12, 2007; accepted February 17, 2008; published online March 25, 2008.

\title{
Supply Chain Risk, Simulation, and Vendor Selection
}

\author{
Desheng $\mathrm{Wu}$ \\ RiskChina Research Center and RiskLab, University of Toronto, Toronto, Ontario, Canada M5S 3G8 \\ (Corresponding author: tel 416 880-5219) \\ David L. Olson \\ Department of Management, University of Nebraska-Lincoln, Lincoln, NE 68588-0491, USA
}

\begin{abstract}
This paper considers three types of risk evaluation models within supply chains: chance constrained programming $(\mathrm{CCP})$, data envelopment analysis (DEA), and multi-objective programming (MOP) models. Various risks are modeled in the form of probability and simulation of specific probability distribution in risk-embedded attributes is conducted in these three types of risk evaluation models. We model a supply chain consisting of three levels and use simulated data with representative distributions. Results from three models as well as simulation models are compared and analysis is conducted. The results show that the proposed approach allows decision makers to perform trade-off analysis among expected costs, quality acceptance levels, and on-time delivery distributions. It also provides alternative tools to evaluate and improve supplier selection decisions in an uncertain supply chain environment.
\end{abstract}

Keywords: supply chain risk management, Monte Carlo simulation, multiple criteria, vendor selection

\section{Introduction}

Supply chains have become major elements in the global economy. One of the most impressive modern manifestations of supply chains is in the form of mammoth retail establishments such as Wal-Mart or Carrefours. In this form, the goods of the world are tapped to be delivered to hundreds of millions of customers in widespread retail outlets. Supply chain participants can include manufacturers at low cost locations such as China, India, or Vietnam, assemblers at high-tech operations in Taiwan and Korea, and distributors where customers reside all over the globe. They can also include ebusiness operations such as Amazon.com.

Supply chains are networks of suppliers/vendors, manufacturers, distributors, and retailers that are connected by transportation, information, and financial infrastructure (Sahin and Robinson, 2002). The ability to specialize and coordinate through e-business has led to complex supply chains that seem to develop from mar- kets rather than the plans of specific organizations (Choi et al., 2001). Current supply chain technology includes potentially many suppliers/vendors linked to one or more manufacturers and/or assemblers, who often use multiple distributors to supply many retailers. Industry supply chain leaders such as i2 and Manugistics have developed tools to share sales and forecast data, and enterprise resource planning software often features such support $(\mathrm{Xu}$ and Dong, 2004).

Supply chains need to provide an adequate service level (minimizing stock-out costs) while controlling overall costs of holding, ordering, transporting, and purchasing. The more permanent relationships found in supply chains often include lower purchasing costs for the core supply chain member, which may pass these savings on to customers (another form of better service). If the vendor (or supplier) has more complete information about demand, they might more efficiently manage their operations. Furthermore, the dynamic environment in 21st Century retail and service makes it necessary to keep up with 
rapid changes in demands, which can complicate holding costs. Callioni et al. (2005) identified four hidden costs of inventory that might be present in supply chains:

1. component devaluation costs - short life value of items or components;

2. price protection costs - if discounts are offered, prior distributors may need to be reimbursed at to the same price level;

3. product return costs - distributors could return unsold goods for full refund;

4. obsolescence costs - product outdating.

A common occurrence in 21st century business is outsourcing product manufacturing. This usually is motivated by lower product costs. There are increased risks expected from differences in product quality, as well as differences in the probabilities of late delivery, as many times lower cost manufacturers are located in developing economies. Desbordes (2007) contended that multinational industries were unlikely to locate foreign activities in risky countries. Sounderpandian et al. (2008) cited the extra lead time variability as well as higher possibilities of material losses in transit. However, there have been many successes in internationally integrated supply chains (Cetindamar et al., 2005; Cadilhon et al., 2005). Many other factors have been considered (Kremic et al., 2006). Another risk-reducing strategy is to rely upon long-term commitments. Swink and Zsidisin (2006) found trade-offs in that firms pursuing longer commitments were subject to risks that might offset short-range benefits. Clearly, selection of supply chain partners is an important decision involving many important factors.

Various models are available to select supply chain partners under conditions of uncertainty and risk. Most researchers (Cohen and Lee, 1988; Lee and Billington, 1993; Thomas and Griffin, 1996; Graves and Willems, 2000; Goetschalckx et al., 2002; Chan, 2003; Chen and Paulraj, 2004) propose deriving probability distribution from historical data and model the SC uncertainty (e.g., uncertain demand) using the derived probability distributions in a decision model. However, these decision models may result in sub-optimal solutions since they typically consider one objective function, e.g., the minimization of expected cost or maximization of expected profit. Multiple criteria are quite often important in selecting supply chain partners and sourcing arrangements (Narasimhan et al., 2006). Research seldom simultaneously considers multiple objective and uncertainty and risk. Simulation-based optimization may provide an alternative approach for dealing with the SC risk and uncertainty, as in Chan and Chan (2006).

This paper considers three types of vendor selection methodologies in supply chains with risk: chance constrained programming (CCP), data envelopment analysis (DEA), and multi-objective programming (MOP) models. Using assumed probability distribution in risk-embedded attributes, we run simulation-based optimization models based on each of these methodologies.

To demonstrate, we model a simple supply chain consisting of three levels and use simulated data with distri- butions empirically derived. Results from three models as well as simulation models are compared and a comprehensive analysis is carried out.

The rest of the paper is organized as follows. Section 2 discusses supply chain risk and three vendor selection methodologies. Section 3 presents three simulation-based optimization models, with results and comparison. Section 4 provides conclusions.

\section{Supply chain risk}

Supply chain operations involve many opportunities to gain the benefits of trade. But they also involve risks. Trade has historically involved risks of shipping, one of the primary motivations for the early insurance industry. Most transportation risks have been brought under control (although piracy still exists, and ships still sink, if only occasionally). But many supply chain risks have been identified. Ojala and Hallikas (2006) analyzed supplier investment risks, and how each could be managed. Wu et al. (2006) classified a broader set of supply chain risks as internal and external, as well as by the level of controllability. Li (2007) modeled supplier risk attitude with respect to risk aversion.

\subsection{Supply chain models}

A variety of models have been resented to aid decision making in supply chains under conditions of risk. Bargbarosoðlu and Yazgaç (2000) applied an AHP model to a set of 72 criteria in categories involving strategic partnership, business and manufacturing performance, and supply chain management. Rabelo et al. (2007) combined AHP with system dynamics in a model involving criteria of profitability, customer satisfaction, responsiveness, and political stability. Kirkwood et al. (2005) gave a multiattribute utility theory model for supply chain configuration, using criteria categories of cost, quality, customer responsiveness, strategic issues, and operating constraints. Wang and Shu (2007) used genetic algorithms for fuzzy data of a supply chain inventory management model. Gaur and Ravindran (2006) used cost and service level in a bicriterion mathematical programming model for supply chain inventory.

This paper considers three types of risk evaluation models within supply chains. CCP allows use of probabilistic constraints within mathematical programming models, and has been applied to supply chain coordination decisions by Barbarosoðlu (2000). CCP also was used by Talluri et al. (2006). DEA provides a means to evaluate relative efficiency of multiple criteria mathematical programming models. DEA has been used by Talluri et al. (2006) in supply chains, and by Wu and Olson (2008) in a vendor selection context. MOP models aim to select preferred vendor by considering the trade-off of various objectives, e.g., cost minimization, quick response, and timely delivery. MOP was used by Weber and Ellram (1992), Weber and Current (1993), and Ghodsypour and O'Brien (2001). 


\subsection{Supply chain risk model}

We model a supply chain consisting of three levels: a set of 10 suppliers, six domestic, and four international, each with expected costs, quality acceptance levels, and on-time delivery distributions. Costs considered are total costs, to include best estimates of the hidden costs discussed in Section 1. Distributions of costs are assumed to be normal, distributions of acceptance failure are assumed to be exponential, and distributions of late delivery are assumed to be lognormal. These represent assumptions that could be replaced by empirically derived distributions. The core level represents the organizing, decision-making retail system. Upstream there are 10 vendors available. The third (downstream) level is represented by 20 customers, each with a demand assumed to be normal for a given period. The retailer must anticipate demand and order quantities of the modeled good to be delivered to arrive on time at each demand destination. Profit is gained from sales made for goods successfully delivered to each demand. Revenue is assumed at $\$ 2$ per item sold. Costs are probabilistic as outlined above, but total cost of goods sold has a mean given for each source supplier. Goods not passing quality acceptance level are not paid for. Goods delivered late are paid for at a reduced rate, and are carried forward at an inventory cost. Table 1 provides data for the supply chain model vendors.

Data given is means (standard deviation); unit costs normally distributed, acceptance rate exponentially distributed, on-time rate lognormally distributed.

Twenty demand sites are modeled, each seeking one common product. Product price is $\$ 2$ per item, time period assumed is a week. Different conditions could be modeled with little difficulty other than scale (Table 2).

\subsubsection{CCP model}

This section uses CCP to model a simplified case: a three-level supply chain with only one customer. Two types of models are used here. One is used to generate orders from suppliers using mathematical programming. A CCP model is considered to model the highest level of complexity assumed (recognizing that any model leaves out some details). Simplified linear programming models are used to generate solutions. The objective function was to maximize expected cost, considering expected losses from acceptance inspection or late delivery. The models differed in the number of variables included:

(1) all 10 potential vendors, and

(2) only the first six vendors, representing domestic sources only.

Minimization of expected cost adjusted for expected loss rates with constraints added to provide buffers for service level (considering quality acceptance and late delivery). This simplification technique is similar to the goal programming approach where we minimize one objective while constraining the remaining objectives to be less than given target values. This method is especially useful if the user can afford to solve just one optimization problem. However, it is not always easy to choose appropriate "goals" for the constraints. Thus, constraint level combinations of $0.90,0.95$, and 0.99 (translating to normal $z$-functions of $1.28,1.64$, and 1.96) for both acceptance and on-time delivery were used, resulting in three additional models. Solutions obtained are given in Table 3:

Table 1. Vendor data

\begin{tabular}{llccr}
\hline Vendor & Unit cost & Accept rate & On-time rate & Maximum \\
\hline V1 & $1.00(0.01)$ & 0.999 & $0.98(0.03)$ & 10,000 \\
V2 & $0.95(0.02)$ & 0.995 & $0.97(0.03)$ & 10,000 \\
V3 & $0.98(0.03)$ & 0.99 & $0.97(0.03)$ & 9000 \\
V4 & $1.03(0.01)$ & 0.98 & $0.98(0.03)$ & 8000 \\
V5 & $1.05(0.05)$ & 0.97 & $0.96(0.03)$ & 8000 \\
V6 & $1.1(0.03)$ & 0.95 & $0.97(0.03)$ & 7000 \\
V7 & $0.75(0.05)$ & 0.98 & $0.90(0.03)$ & 10,000 \\
V8 & $0.60(0.06)$ & 0.95 & $0.88(0.03)$ & 8000 \\
V9 & $0.55(0.07)$ & 0.90 & $0.86(0.03)$ & 6000 \\
V10 & $0.50(0.08)$ & 0.80 & $0.85(0.03)$ & 4000 \\
\hline
\end{tabular}

Table 2. Demand data

\begin{tabular}{lrc}
\hline Demand & Average (std) & Minimum per period \\
\hline D1 & $3000(300)$ & 1000 \\
D2 & $2800(300)$ & 1000 \\
D3 & $2200(300)$ & 1000 \\
D4 & $1800(300)$ & 1000 \\
D5 & $1500(300)$ & 500 \\
D6 & $1300(300)$ & 500 \\
D7 & $1200(250)$ & 500 \\
D8 & $1200(250)$ & 500 \\
D9 & $1200(250)$ & 400 \\
D10 & $1100(250)$ & 300 \\
D11 & $1100(250)$ & 200 \\
D12 & $1100(200)$ & 100 \\
D13 & $800(200)$ & 0 \\
D14 & $700(150)$ & 0 \\
D15 & $500(150)$ & 0 \\
D16 & $300(100)$ & 0 \\
D17 & $300(100)$ & 0 \\
D18 & $200(100)$ & 0 \\
D19 & $200(50)$ & 0 \\
D20 & $200(50)$ & 0 \\
\hline
\end{tabular}

Table 3. Decisions obtained from CCP

\begin{tabular}{lrrrrr}
\hline \multicolumn{2}{l}{ Ordered } & Base Domestic & At 0.9 & At 0.95 & At 0.99 \\
\hline V1 & 0 & 4,500 & 0 & 0 & 0 \\
V2 & 0 & 10,000 & 1,157 & 1,536 & 2,246 \\
V3 & 0 & 9,000 & 0 & 0 & 0 \\
V4 & 0 & 0 & 0 & 0 & 0 \\
V5 & 0 & 0 & 0 & 0 & 0 \\
V6 & 0 & 0 & 0 & 0 & 0 \\
V7 & 9,805 & 0 & 10,000 & 10,000 & 10,000 \\
V8 & 8,000 & 0 & 8,000 & 8,000 & 8,000 \\
V9 & 6,000 & 0 & 6,000 & 6,000 & 6,000 \\
V10 & 4,000 & 0 & 4,000 & 4,000 & 4,000 \\
\hline
\end{tabular}


Vendors selected by CCP fits those by MOP model in Section 2.2.1. V2, V7-10 are frequently selected by both CCP and MOP. V4, V5, and V6 are never selected by CCP and V 5 and V6 are never selected by MOP.

\subsubsection{DEA model}

DEA can be used for a comparison and constitutes a useful complement to the available decision models for supplier selection. DEA is used to establish a best practice group amongst a set of observed units and to identify the units that are inefficient when compared to the best practice group. DEA also indicates the magnitude of the inefficiencies and improvements possible for the inefficient units. Consider $n$ DMUs to be evaluated, $\operatorname{DMU}_{j}(j=$ $1,2, \ldots n)$ that consumes the amounts $X_{j}=\left\{x_{i j}\right\}$ of $m$ different of inputs $(i=1,2, \ldots, m)$ and produces the amounts $Y_{j}=\left\{y_{r j}\right\}$ of $r$ outputs $(r=1, \ldots, s)$. The input-oriented efficiency of a particular $\mathrm{DMU}_{0}$ under the assumption of constant returns to scale can be obtained from the following primal-dual linear programs (input-oriented CCR model (Charnes et al., 1978)):

$$
\begin{aligned}
\min _{\theta, \lambda, s^{+}, s^{-}} z_{0}=\theta-\varepsilon \overrightarrow{1} s^{+}-\varepsilon \overrightarrow{1} s^{-} \\
\text {subject to } Y \lambda-s^{+}=Y_{0} \\
\theta X_{0}-X \lambda-s^{-}=0 \\
\lambda, s^{+}, s^{-} \geq 0
\end{aligned}
$$

where $s^{+}$and $s^{-}$are the slacks in the system.

$$
\begin{aligned}
& \max _{\mu, \nu} w_{0}=\mu^{T} Y_{0} \\
& \mu^{T} Y-v^{T} X \leq 0 \\
& -\mu^{T} \leq-\varepsilon \overrightarrow{1} \\
& -v^{T} \leq-\varepsilon \overrightarrow{1}
\end{aligned}
$$

Performing a DEA analysis requires the solution of $n$ linear programming problems of the above form, one for each DMU. The optimal value of the variable $\theta$ indicates the proportional reduction of all inputs for $\mathrm{DMU}_{0}$ that will move it onto the frontier, which is the envelopment surface defined by the efficient DMUs in the sample. A DMU is termed efficient if and only if the optimal value $\theta^{*}$ is equal to 1 and all the slack variables are zero.

Each DEA model seeks to determine which of the $n$ candidate vendors define an envelopment surface that represents best practice, referred to as the efficient frontier. Units that lie on the surface are deemed efficient in DEA while those units that do not, are termed inefficient. DEA provides a comprehensive analysis of relative efficiencies for multiple input-multiple output situations by evaluating each vendor and measuring its performance relative to an envelopment surface composed of other vendors. DEA "scans" the available suppliers and identifies the efficient subset of suppliers. Those vendors known as the efficient reference set are the peer group for the inefficient units. Thus, a DEA model can serve as a "filter" before the determination of final selected suppliers. Various DEA models are available and many model extensions can be used to provide a more comprehensive review of candidate vendor performance (wu, 2008). For example, we can use categorical variables such as the competitive environment and vendor location to enhance the model and add additional variables to either model if more vendors become available for study. We can also add weight restrictions to the models to refine the results and lead to more realistic recommended improvements. We will develop DEA simulation models to implement some extensions while keep others as further considerations.

\subsubsection{MOP model}

An MOP model is given in the appendix. This model differs from various models reported in the literature, e.g., Weber and Ellram (1992), Weber and Current (1993), and Ghodsypour and O'Brien (2001) due to the consideration of different demand risk from many different customers. We only consider a single assembler, who has only one attribute, i.e., demand.

This model simultaneously minimizes the purchase cost $\left(f_{1}\left(x_{i j}\right)\right)$, percentage of items delivered late $\left(f_{2}\left(x_{i j}\right)\right)$ and percentage of items rejected $\left(f_{3}\left(x_{i j}\right)\right)$, while meeting various constraints, e.g. with respect to minimum and maximum order quantities. These goals were also used by Narasimhan et al. (2006) in a multi-criteria mathematical programming supply chain model. We have lower and upper bound for $x_{i j}$ from both the vendor and the customer's point of view, as expressed in constraints (5)-(8). We note that it is not obvious how to treat the various goals (Steuer, 1986). For example, the goals might be minimized sequentially or weights might be introduced making it a single criterion search problem, much as the weighted sum of various objectives approach or goal programming approach (Narasimhan et al., 2006).

A standard technique for MOP is to minimize a positively weighted convex sum of the objectives, that is, $\operatorname{Min} \Sigma_{q} \omega_{q} f_{q}\left(x_{i j}\right)$, where the weights of three objectives can be expressed by $\left(\omega_{1}, \omega_{2}, \omega_{3}\right)$ with $\Sigma \omega_{q}=1, q=1, \ldots, 3,0<$ $\omega_{\mathrm{q}}<1$. It is easy to prove that the minimizer of this combined function is Pareto optimal. It is up to the user to choose appropriate weights. Though computationally more expensive, this approach gives an idea of the shape of the Pareto surface and provides the user with more information about the trade-off among the various objectives. In order to examine the customer's preference over different objectives, three scenarios are analyzed in terms of weight attached to three objectives: $\left(\omega_{1}, \omega_{2}, \omega_{3}\right)=(0.6$, $0.2,0.2),\left(\omega_{1}, \omega_{2}, \omega_{3}\right)=(0.2,0.6,0.2)$ and $\left(\omega_{1}, \omega_{2}, \omega_{3}\right)=(0.2$, $0.2,0.6$ ). This scenario analysis is necessary since the buyer's procurement priorities tend to shift from quality and delivery performance $\left(\left(\omega_{1}, \omega_{2}, \omega_{3}\right)=(0.2,0.6,0.2)\right.$ and $\left(\left(\omega_{1}\right.\right.$, $\left.\left.\omega_{2}, \omega_{3}\right)=(0.2,0.2,0.6)\right)$ to cost minimization $\left(\left(\omega_{1}, \omega_{2}, \omega_{3}\right)=\right.$ $(0.6,0.2,0.2))$, particularly in a case product life cycle is taken into consideration (Narasimhan et al., 2006).

Table 4 presents supplier selected and order quantity from MOP models. As can be seen from Table 4, the buyer's selecting of suppliers and ordering quantity change as his preference over different objectives changes. When the weight attached to cost objective is larger, the buyer tends 
Table 4. Supplier selected and order quantity from MOP

\begin{tabular}{|c|c|c|c|c|c|c|c|c|c|c|c|c|}
\hline \multirow{2}{*}{$\begin{array}{l}\begin{array}{l}\text { Customer } \\
\text { (demand) }\end{array} \\
\text { D1 }\end{array}$} & \multicolumn{4}{|c|}{$\left(\omega_{1}, \omega_{2}, \omega_{3}\right)=(0.6,0.2,0.2)$} & \multicolumn{4}{|c|}{$\left(\omega_{1}, \omega_{2}, \omega_{3}\right)=(0.2,0.6,0.2)$} & \multicolumn{4}{|c|}{$\left(\omega_{1}, \omega_{2}, \omega_{3}\right)=(0.2,0.2,0.6)$} \\
\hline & V10 & V9 & 2000 & 1000 & V8 & V7 & 2000 & 1000 & V8 & V2 & 2000 & 1000 \\
\hline D3 & V9 & V8 & 1200 & 1000 & V8 & V7 & 1200 & 1000 & V8 & V2 & 1200 & 1000 \\
\hline D4 & V9 & V8 & 1000 & 1000 & V8 & V7 & 1000 & 1000 & V8 & V2 & 1000 & 1000 \\
\hline D5 & V9 & V8 & 1000 & 500 & V8 & V7 & 1000 & 500 & V8 & V2 & 1000 & 500 \\
\hline D7 & V8 & V7 & 700 & 500 & V9 & V7 & 500 & 700 & $\mathrm{~V} 2$ & V1 & 700 & 500 \\
\hline D8 & V8 & V7 & 700 & 500 & V9 & V7 & 500 & 700 & V2 & V1 & 700 & 500 \\
\hline D9 & V8 & V7 & 800 & 400 & V9 & V7 & 400 & 800 & V2 & V1 & 800 & 400 \\
\hline D10 & V8 & V7 & 800 & 300 & V9 & V7 & 300 & 800 & V2 & $\mathrm{V} 1$ & 800 & 300 \\
\hline D11 & V10 & V8 & 200 & 900 & V9 & V7 & 200 & 900 & V2 & V1 & 900 & 200 \\
\hline D12 & V8 & V7 & 1000 & 100 & V8 & V7 & 200 & 900 & V8 & $\mathrm{V} 2$ & 200 & 900 \\
\hline D17 & V7 & V4 & 299 & 1 & V9 & V2 & 297 & 3 & V9 & V1 & 2 & 298 \\
\hline D18 & V7 & $\mathrm{V} 4$ & 199 & 1 & V9 & $\mathrm{V} 2$ & 197 & 3 & V9 & V1 & 2 & 198 \\
\hline D19 & V7 & $\mathrm{V} 4$ & 199 & 1 & V2 & V9 & 3 & 197 & V9 & V1 & 2 & 198 \\
\hline D20 & V7 & V4 & 199 & 1 & V9 & $\mathrm{V} 2$ & 197 & 3 & V9 & V1 & 2 & 198 \\
\hline
\end{tabular}

to choose V7, V8, V9, and V10, which can provide lower unit cost than the rest. Those providing high unit cost, i.e., V1-V3, V5, and V6 are never selected by any customer. Moreover, for the two selected suppliers, the customer prefer to order more from the supplier providing lower unit cost than from the one providing higher unit cost. For example, as shown in the second and third row of Table 4, both D1 and D2 selected V10 and V9. Both D1 and D2 order more from V10 than from V9 since V10 provides an average unit cost 0.5 , which is lower than 0.55 by V9.

As the buyer's procurement priorities shift from cost minimization to quality and delivery performance, V1 and V2, which can provide high quality and delivery performance, are more preferred by the buyer. Those providing poor quality and delivery performance, e.g., V10 are unlikely to be selected.

\section{Simulation}

This section presents three simulation models: a Monte Carlo simulation applied to the MOP model, another to the CCP model, and a third to the DEA simulation model. Monte Carlo simulation applied to the CCP model generates quite consistent results with simulation of the DEA model. Simulation applied to the MOP model considers risks across various customers, which is a more complicated situation than that in the other two models.

\subsection{A Monte Carlo simulation applied to CCP model}

Using Excel and Crystal Ball, the five ordering plans were used with the assumed distributions, calculating expected profit, end of period excess or shortage, rejected
Table 5. Simulation means - CCP Model

\begin{tabular}{lrrrrr}
\hline & Base & Domestic & At 0.9 & At 0.95 & At 0.99 \\
\hline Profit & 23,864 & 15,166 & 24,778 & 25,027 & 25,494 \\
Excess & 225 & 15,166 & 339 & 370 & 441 \\
Short & 8,373 & 7,861 & 7,638 & 7,428 & 7,047 \\
Rejects & 9,968 & 7,814 & 10,405 & 10,527 & 10,756 \\
Late & 3,302 & 827 & 3,368 & 3,384 & 3,413 \\
Service level & 0.63 & 0.66 & 0.67 & 0.67 & 0.69 \\
\hline
\end{tabular}

items, and late items. Profit was calculated as $\$ 2$ times the minimum of items purchased by policy minus rejected or late items, and sum of customer demand, less $\$ 0.01$ per excess item to reflect inventory carrying cost. The simulation was implemented in Crystal Ball, an Excel add-on, which provides means to easily generate probability distributions. Each vendor had three probabilistic elements: cost, acceptance, and on-time delivery, as given earlier. To control for random differences across policies, the outcomes (profit, rejections, late deliveries) were applied to each of the five policies in each model. One thousand runs were conducted. Means obtained for aggregate measures are given in Table 5.

\subsection{Simulation of DEA model}

To investigate and illustrate the performance of the candidate vendors and compare the results to those from other models, we have carried out three simulations: 200 simulation runs, 600 simulation runs, and 1000 simulation runs. Input and output data are randomly generated using the assumed distributions in each of these simulation runs. We estimate the DEA efficiency score given to each 
Table 6. Computation from simulation of DEA model

\begin{tabular}{|c|c|c|c|c|c|c|c|c|c|c|c|c|}
\hline Vendor & \multicolumn{4}{|c|}{200 simulation runs } & \multicolumn{4}{|c|}{600 simulation runs } & \multicolumn{4}{|c|}{1500 simulation runs } \\
\hline V2 & 0.642 & 0.148 & 0.02 & 19 & 0.637 & 0.142 & 0.011 & 44 & 0.636 & 0.146 & 0.007 & 109 \\
\hline V3 & 0.621 & 0.147 & 0.02 & 12 & 0.626 & 0.144 & 0.011 & 38 & 0.622 & 0.146 & 0.007 & 96 \\
\hline V6 & 0.555 & 0.145 & 0.02 & 10 & 0.567 & 0.159 & 0.012 & 43 & 0.559 & 0.148 & 0.007 & 72 \\
\hline V7 & 0.751 & 0.15 & 0.02 & 29 & 0.752 & 0.145 & 0.01 & 82 & 0.742 & 0.148 & 0.007 & 209 \\
\hline V8 & 0.876 & 0.132 & 0.018 & 68 & 0.872 & 0.13 & 0.01 & 192 & 0.877 & 0.129 & 0.006 & 514 \\
\hline V9 & 0.914 & 0.116 & 0.016 & 89 & 0.913 & 0.109 & 0.008 & 271 & 0.922 & 0.109 & 0.005 & 759 \\
\hline
\end{tabular}

vendor of interests each time we run DEA. We finally calculate the average DEA efficiency scores and standard deviation in the total runs. Table 6 presents the average efficiency score, standard derivation, the $95 \%$ of confidence interval for the mean and the percentage (number) of efficient DMUs in the stochastic DEA simulation models. Table 6 reports results.

From Table 6, it is evident that based on the simulation, the three vendors with the worst performance were V3, V4, and V5. This is consistent with that resulted from a Monte Carlo simulation to CCP in Section 3.1.

\subsection{Simulation of MOP model}

We consider stochastic demand from various customers in a simulation of an MOP model to see the change of vendor selection with respect to demand variation across various customers. As mentioned in Section 2.2, we can introduce weights to aggregate various objectives into a single criterion. Thus, the MOP binary programming problem can be solved using a series of linear programming models. To explain this, we develop the following algorithm to solve the MOP problem coupled with stochastic data and select two vendors for each customer.

\section{Algorithm: simulation in MOP}

Step 1: Initialize the weights of different objectives, i.e., total purchase amount cost, items rejected rate, and late delivery. Set the total number of candidate suppliers and total number of customer. Set upper and lower bounds for decision variables in constraints (5)-(8).

Step 2: Define the distribution of cost, rejected rate, late delivery and demand, and set the value of related parameters. Set the number of simulation runs and generate experiment data according to defined distributions.

Step 3: denote by $i$ the indicator of the candidate customer, set the initial value of $i$ to unity.

Step 4: denote by $j_{-} 1$ the indicator of the 1st supplier and $j \_2$ the indicator of the 2 nd supplier; set the initial value of $j \_1$ and $j \_2$ to unity.

Step 5: if $j_{-} 1=j_{-} 2$, set $j \_2=j \_2+1$ and go to Step 6 .

Step 6: Solve the following linear program:

$$
\begin{aligned}
& \operatorname{ming}_{i}\left(x_{i 1}, x_{i 2}\right)=\omega_{1} \sum_{j=1}^{2} c_{i j} x_{i j}+\omega_{2} \sum_{j=1}^{2} \beta_{i j} x_{i j}+\omega_{3} \sum_{j=1}^{2} \lambda_{i j} x_{i j} \\
& \text { subject to : } \\
& \quad x_{i 1}+x_{i 2} \geq D_{i}, \forall i \\
& x_{i j} \leq u_{i j^{\prime}}^{u} \forall i, j \\
& x_{i j} \leq w_{i j^{\prime}}^{u} \forall i, j \\
& x_{i j} \geq u_{i i^{\prime}}^{l^{\prime}} \forall i, j \\
& x_{i j} \geq w_{i j^{\prime}}, \forall i, j
\end{aligned}
$$

Denote by $g_{i}^{*} x_{i 1}^{*}$, and $x_{i 2}^{*}$ the optimal objective value and optimal values of the variables to above linear program.

Step 7 : Set $j \_2=j \_2+1$. If $j \_2>$ the total number of candidate suppliers, set $j \_2=1$ and go to Step 8 ; otherwise go to Step 5.

Step 8: Set $j_{1} 1=j_{-} 1+1$. If $j_{-} 1>$ the total number of candidate suppliers, set $j \_1=1$ and go to Step 9; otherwise go to Step 5.

Step 9: For the $i$ th customer, find the combination (j_1, $\left.j \_2\right)$, such that the objectives achieves minimum; Denote $J_{i}$ $\left(j \_1, j \_2\right)$ the corresponding order quantity,

i.e., $J_{i}\left(j \_1, j \_2\right)=\arg \min _{j \_1, j \_} f_{i}\left(x_{i j \_}, x_{i j \_}\right)$.

Step 10: Set $i=i+1$. If $i>$ total number of customer, go to Step 11; otherwise go to Step 4.

Step 11: Generate statistic result after all simulation runs are done.

Using Matlab codes, the algorithm was implemented with the assumed distributions, calculating minimal cost, rejected items, and late items. We carried out 600 simulation runs. Weights attached to the three objectives were assumed to be independently identically distributed with uniform distribution in the interval $(0,1)$.

Tables 7-9 document computational results. Table 7 presents the total cost, items rejected, and late rate for each customer. Table 8 presents optimal order quantity 
Table 7. Minimum total cost, items rejected, and late rate for each customer

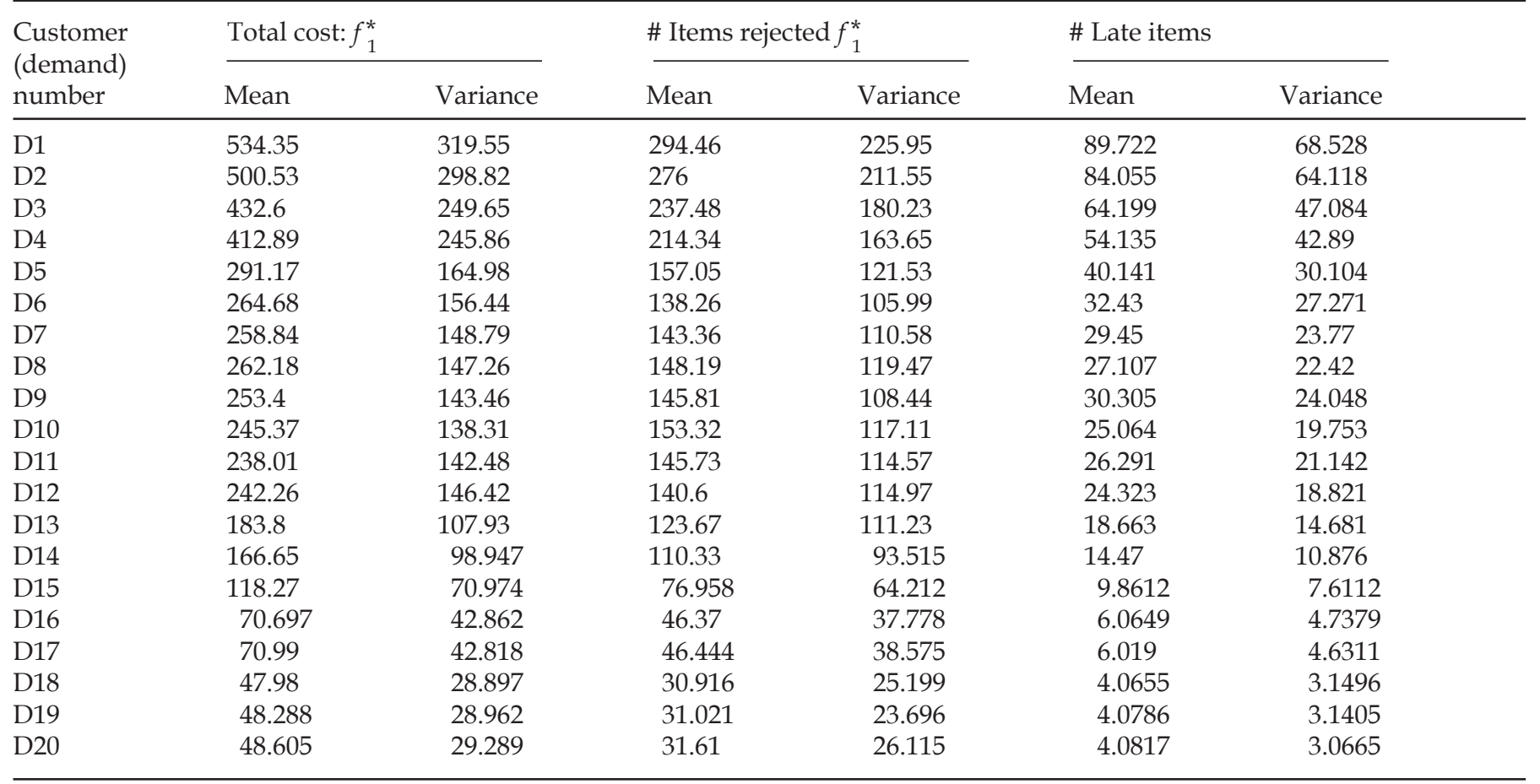

from two suppliers and Table 9 presents the probability of each customer's choice of suppliers.

From simulation results of the MOP model, we observe some interesting patterns: First, every vendor is likely to be selected by some buyers. Second, buyers expecting more demands are likely to have more total cost, items rejected, and higher late delivery rate, which can be seen from Table 7. Third, from Table 9, when demand is high and demand uncertainty is severe, e.g., the demands faced by D1-6, the customers tend to select vendors V8, 9, and 10 in order to maintain low purchasing cost. It seems that these buyers cares more about cost than quality and on-time delivery since they are less likely to select V1-V4, which can provide better quality and on-time delivery. D15-20 are more likely to choose V4 and V6, which provide a mediate unit cost and reasonably good quality and on-time delivery. The probability of choosing V4, V5, and V6 by most buyers are low, which is consistent with the results from CCP, MOP, and DEA simulation.

\section{Conclusions}

CCP models provide the ability to incorporate probabilities directly into models. DEA models guarantee nondominated solutions, but do not incorporate decision maker preference functions that enable identification of preferred solutions. A comparison of selected vendors resulted from the three approaches are compared. The CCP model selected V7, V8, V9, and V10, given "goals" of acceptance and on-time delivery for the constraints (see Table 4). The DEA simulation model selected V7-V10 as the four most favorable vendors, with the ranking order as $\mathrm{V} 10>\mathrm{V} 9>$ V8 > V7 (see Table 6). In the MOP model, all customers prefer to choose among V7-V10 if the cost goal is emphasized, which can be seen from Table 3 where the weights are chosen as $(w 1, w 2, w 3)=(0.6,0.2,0.2)$. The MOP model provides flexibility for decision makers to reflect their preference over different criteria. Different preference over different criteria leads to different vendors selected.

All three models identify V4-V6 as dominated vendors. The MOP simulation models selected a different set of vendors for different customer preference sets of weights. V7-V10 are selected with high probability under high demand status.

Table 8. Order quantity from two suppliers

\begin{tabular}{|c|c|c|c|}
\hline \multicolumn{2}{|c|}{ Quantity from the 1st vendor V1 } & \multicolumn{2}{|c|}{ Quantity from the 2nd vendor V2 } \\
\hline Mean & Variance & Mean & Variance \\
\hline 1520 & 499.6 & 1480 & 499.6 \\
\hline 1416 & 399.68 & 1384 & 421.9 \\
\hline 1080 & 97.98 & 1120 & 144.83 \\
\hline 1000 & $1.8707 \mathrm{e}-009$ & 1000 & $1.8707 \mathrm{e}-009$ \\
\hline 695 & 243.87 & 805 & 266.65 \\
\hline 605 & 143.09 & 695 & 143.09 \\
\hline 560 & 91.652 & 640 & 131.34 \\
\hline 562 & 92.499 & 638 & 120.42 \\
\hline 515 & 161.48 & 685 & 175.45 \\
\hline 529 & 240.54 & 571 & 264.17 \\
\hline 430 & 306.1 & 670 & 310.93 \\
\hline 469 & 392.1 & 631 & 396.09 \\
\hline 361.28 & 358.28 & 438.72 & 359.2 \\
\hline 336.12 & 337.87 & 363.88 & 334.74 \\
\hline 247.05 & 245.47 & 252.95 & 245.45 \\
\hline 146.09 & 146.11 & 153.91 & 145.7 \\
\hline 146.22 & 145.39 & 153.78 & 145.4 \\
\hline 92.25 & 97.828 & 107.75 & 97.55 \\
\hline 99.86 & 95.688 & 100.14 & 95.627 \\
\hline 86.3 & 97.163 & 113.7 & 95.957 \\
\hline
\end{tabular}


Table 9. Probability of every customer's choice of suppliers

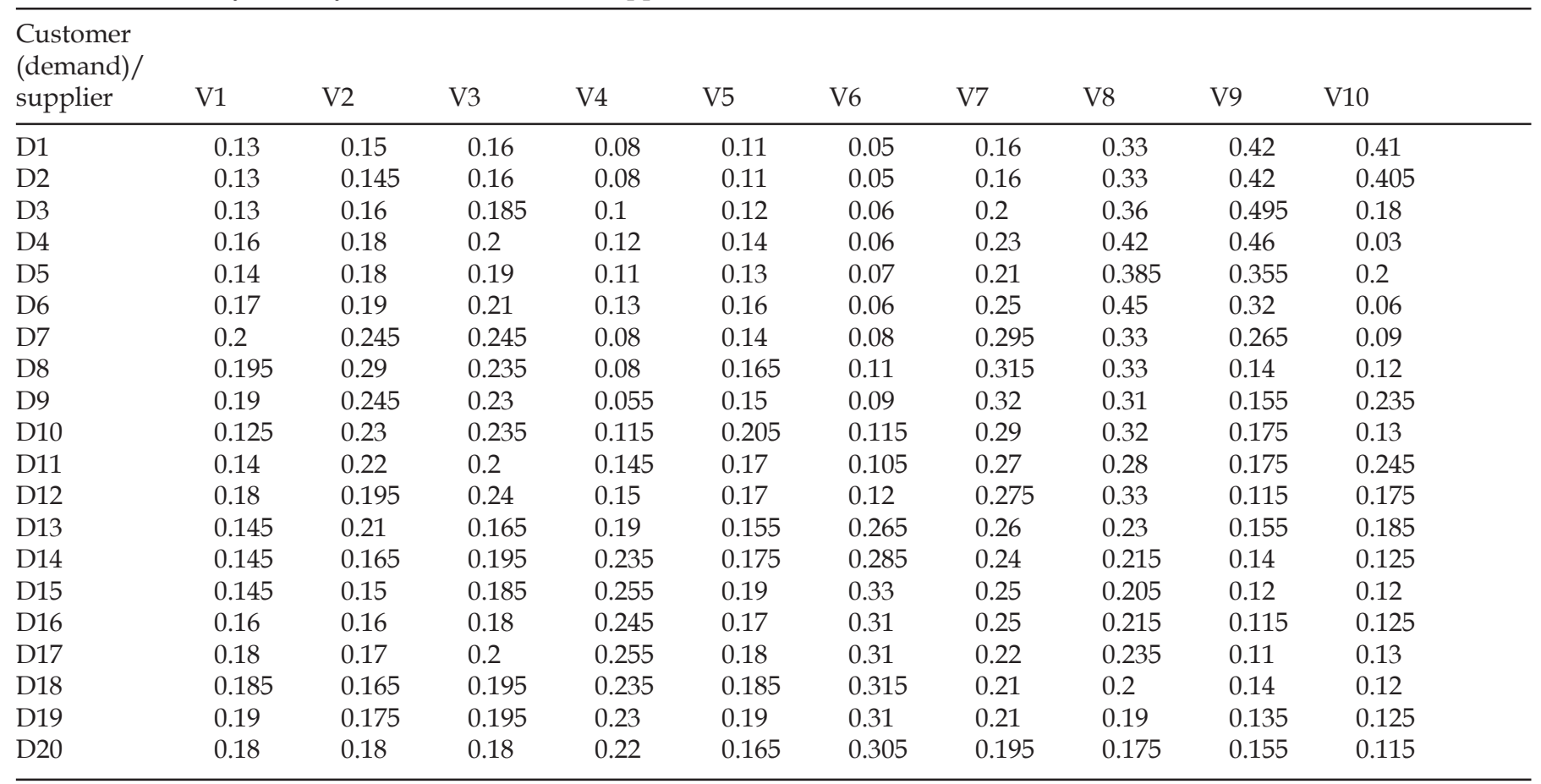

We have modeled a supply chain consisting of three levels and used simulated data representative of such a supply chain. We have proposed an algorithm to solve the proposed MOP model as well as the corresponding simulation model. Various risks in both supply and demand perspective were modeled in the form of probability and simulation of representative probability distributions in risk-embedded attributes. Simulation allows users to apply whatever probability distributions exist in their particular applications. Results from three models as well as simulation models are consistent with each other in selecting preferred suppliers taking risk factors into consideration. The results verified our proposed model and show that the proposed approach allows decision makers to perform trade-off analysis among expected costs, quality acceptance levels, and on-time delivery distributions. CCP, DEA, and MOP models provide alternative tools to evaluate and improve supplier selection decisions in an uncertain SC environment.

\section{Appendix: Multiple criteria model}

Notations in the MOP model are defined as follows:

$n_{i} \quad$ the total number of candidate suppliers of interests

$n_{i} \quad$ the number of candidate suppliers desired by the $i$ th customer

$x_{i j} \quad$ decision variables, quantity purchased by the $i$ th customer from supplier $j$

$z_{i j} \quad$ decision variables $=1$ if supplier $j$ is selcted by the $i$ th customer; 0 otherwise

$c_{i j} \quad$ per unit purchase cost from supplier $j$ by the $i$ th customer

$\lambda_{i j} \quad$ percentage of items late from supplier $j$ to the $i$ th customer

$\beta_{i} \quad$ percentage of rejected units from supplier $j$

D total demand for the item

$D_{i} \quad$ demand for item over planning period from the $i$ th customer

$u_{i j}{ }^{\mathrm{u}} \quad$ maximum amount of business for item to be given to supplier $j$ by the $i$ th customer

$u_{i j}{ }^{1} \quad$ minimum amount of business for item to be given to supplier $j$ by the $i$ th customer

$w_{i j}{ }^{\mathrm{u}} \quad$ maximum order quantity from supplier $j$ by the $i$ th customer

$w_{i j}^{1} \quad$ minimum order quantity from supplier $j$ by the $i$ th customer 
Objectives and constraints are defined as follows:

Objective 1 Minimize the total purchase cost.

Objective 2

Objective 3

Constraint 4

Constraint 5

Constraint 6

Constraint 7

Constraint 8

Constraint 9

Minimize the number of rejected items.

Minimize the number of late deliveries.

Ensures that the quantity demand is met.

Ensures that the vendor's capacity is not exceeded.

Ensures that the customer's proposed business to the vendor is not exceeded.

Establishes minimum order quantities the vendors supply.

Establishes minimum business for selected vendors.

Ensures that there are no negative orders.

Constraint 10 Establishes binary nature of vendor selection decision.

$$
\begin{aligned}
& \operatorname{Min} f_{1}\left(x_{i j}\right)=\sum_{i=1}^{m} \sum_{j=1}^{n_{i}} c_{i j} x_{i j} \quad\{\text { total cost }\} \\
& \operatorname{Min} f_{2}\left(x_{i j}\right)=\sum_{i=1}^{m} \sum_{j=1}^{n_{i}} \beta_{i j} x_{i j} \quad\{\text { \# rejected }\} \\
& \operatorname{Min} f_{3}\left(x_{i j}\right)=\sum_{i=1}^{m} \sum_{j=1}^{n_{i}} \lambda_{i j} x_{i j} \quad\{\# \text { late }\} \\
& \text { subject to: } \\
& \sum_{j} x_{i j} \geq D_{i}, i=1, \ldots, m \\
& x_{i j} \geq z_{i j} u_{i j}^{l}, \forall i, j \\
& x_{i j} \geq z_{i j} u_{i j}^{u}\{\text { lower and upper business bound set for the purchased amount } \forall i, j\} \\
& x_{i j} \geq z_{i j} w_{i j}^{l}, \forall i, j \\
& x_{i j} \geq z_{i j} w_{i j}^{u}, \forall i, j \quad\{\text { lower and upper order bound set for the purchased amount } \forall i, j\} \\
& \sum_{j} z_{i j}=n_{i}\{\# \text { of vendors satisfy desired number }\} \\
& x_{i j} \geq 0 \\
& z_{i j}=\{0,1\}, \forall i, j \\
& \quad \text { where } j=1, \ldots, n_{i} \text { represents the possible vendors selected for the } i \text { th customer. }
\end{aligned}
$$

\section{References}

Barbarosoðlu, 2000 • G. Barbarosoðlu, An integrated supplier-buyer model for improving supply chain coordination, Production Planning \& Control 11 (8) (2000), pp. 732-741.

Bargbarosoðlu and Yazgaç, $2000 \bullet$ G. Bargbarosoðlu and T. Yazgaç, A decision support model for customer value assessment and supply quota allocation, Production Planning $\mathcal{E}$ Control 11 (6) (2000), pp. 608-616.

Cadilhon et al., $2005 \bullet$ J.-J. Cadilhon, A.P. Fearne, P. T. G. Tam, P. Moustier and N. D. Poole, Collaborative commerce or just common sense? Insights from vegetable supply chains in Ho Chi Minh City, Supply Chain Management 10 (3) (2005), pp. 147-149.

Callioni et al., 2005 - G. Callioni, X. de Montros, R. Slagmulder, L. N. Van Wassenhove and L. Wright, Inventorydriven costs, Harvard Business Review 82 (3) (2005), pp. 135-140.

Cetindamar et al., $2005 \bullet$ D. Cetindamar, B. Çatay and O. S. Basmaci, Competition through collaboration: Insights from an initiative in the Turkish textile supply chain, Supply Chain Management 10 (4) (2005), pp. 238-240.

Chan, 2003 - F. T. S. Chan, Interactive selection model for supplier selection process: An analytical hierarchy process approach, International Journal of Production Research 41 (15) (2003), pp. 3549-3579.

Chan and Chan, $2006 \bullet$ F. T. S. Chan and H. K. Chan, A simulation study with quantity flexibility in a supply chain subjected to uncertainties, International Journal of Computer Integrated Manufacturing 19 (2) (2006), pp. 148-160.

Charnes et al., $1978 \bullet$ A. Charnes, W. W. Cooper, and E. Rhodes, A Data envelopment analysis approach to evaluation of the program follow through experiments in US public school education. Management Science Research Report No. 432. Pittsburgh, Carnegie-Mellon University, School of Urban and Public Affairs, 1978.

Chen and Paulraj, 2004 • I. J. Chen and A. Paulraj, Understanding supply chain management: Critical research and a theoretical framework, International Journal of Production Research 42 (1) (2004), pp. 131-163.

Choi et al., 2001 • T. Y. Choi, K. J. Doole and M. Rungtusanatham, Supply networks and complex adaptive systems: 
Control versus emergence, Journal of Operations Management 19 (2001), pp. 351-366.

Cohen and Lee, $1988 \bullet$ M. A. Cohen and H. L. Lee, Strategic analysis of integrated production-distribution systems: Models and methods, Operations Research 36 (2) (1988), pp. 216-228.

Desbordes, $2007 \bullet$ R. Desbordes, The sensitivity of US multinational enterprises to political and macroeconomic uncertainty: A sectoral analysis, International Business Review 16 (6) (2007), pp. 732-750.

Gaur and Ravindran, 2006 • S. Gaur and A. R. Ravindran, A bi-criteria model for the inventory aggregation problem under risk pooling, Computers $\mathcal{E}$ Industrial Engineering 51 (2006), pp. 482-501.

Ghodsypour and O'Brien, 2001 - S. H. Ghodsypour and C. $\mathrm{O}^{\prime}$ Brien, The total cost of logistic in supplier selection, under conditions of multiple sourcing, multiple criteria and capacity constraint, International Journal of Production Economics 73 (2001), pp. 15-27.

Goetschalckx et al., $2002 \bullet$ M. Goetschalckx, C. J. Vidal and K. Dogan, Modeling and design of global logistics systems: A review of integrated strategic and tactical models and design algorithms, European Journal of Operational Research 143 (1) (2002), pp. 1-18.

Graves and Willems, 2000 • S. C. Graves and S. P. Willems, Optimizing strategic safety stock placement in supply chains, Manufacturing \& Service Operations Management 2 (1) (2000), pp. 68-83.

Kirkwood et al., $2005 \bullet$ C. W. Kirkwood, M. P. Slaven and A. Maltz, Improving supply-chain-reconfiguration decisions at IBM, Interfaces 35 (6) (2005), pp. 460-473.

Kremic et al., 2006 - T. Kremic, O. I. Tukel and W. O. Rom, Outsourcing decision support: A survey of benefits, risks, and decision factors, Supply Chain Management: An International Journal 11 (6) (2006), pp. 467-482.

Lee and Billington, $1993 \bullet$ H. L. Lee and C. Billington, Material management in decentralized supply chain, Operations Research 41 (5) (1993), pp. 835-847.

Li, $2007 \bullet$ Q. Li, Risk, risk aversion and the optimal time to produce, IIE Transactions 39 (2007), pp. 145-158.

Narasimhan et al., $2006 \bullet$ R. Narasimhan, S. Talluri and S. K. Mahapatra, Multiproduct, multicriteria model for supplier selection with product life-cycle considerations, Decision Sciences 37 (4) (2006), pp. 577-603.

Ojala and Hallikas, $2006 \bullet$ M. Ojala and J. Hallikas, Investment decision-making in supplier networks: Management of risk, International Journal of Production Economics 104 (2006), pp. 201-213.

Rabelo et al., $2007 \bullet$ L. Rabelo, H. Eskandari, T. Shaalan and M. Helal, Value chain analysis using hybrid simulation and AHP, International Journal of Production Economics 105 (2007), pp. 536-547.

Sahin and Robinson, $2002 \bullet$ F. Sahin and E. P. Robinson, Flow coordination and information sharing in supply chains: Review, implications, and directions for future research, Decision Sciences 33 (4) (2002), pp. 505-536.

Sounderpandian et al., $2008 \bullet$ J. Sounderpandian, S. Prasad and M. Madan, Supplies from developing countries: Optimal order quantities under loss risks, Omega 36 (1) (2008), pp. 122-130.

Steuer, 1986 - R. E. Steuer, Multiple Criteria Optimization: Theory, Computation, and Application, Wiley, New York (1986).

Swink and Zsidisin, $2006 \bullet$ M. Swink and G. Zsidisin, On the benefits and risks of focused commitment to suppliers, International Journal of Production Research 44 (20) (2006), pp. 4223-4240.

Talluri et al., 2006 - S. Talluri, R. Narasimhan and A. Nair, Vendor performance with supply risk: A chance-constrained DEA approach, International Journal of Production Economics 100 (2006), pp. 212-222.

Thomas and Griffin, $1996 \bullet$ D. J. Thomas and P. M. Griffin, Coordinated supply chain management, European Journal of Operational Research 94 (1) (1996), pp. 1-15.

Wang and Shu, 2007 • J. Wang and Y.-F. Shu, A possibilistic decision model for new product supply chain design, European Journal of Operational Research 177 (2007), pp. 1044-1061.

Weber and Ellram, 1992 • C. A. Weber and L. M. Ellram, Supplier selection using multi-objective programming: A decision support system approach, International Journal of Physical Distribution \& Logistics Management 23 (2) (1992), pp. 3-14.

Weber and Current, 1993 • C. A. Weber and J. R. Current, A multiobjective approach to vendor selection, European Journal of Operational Research 68 (1993), pp. 173-184.

Wu, 2008 - Wu, D., 2008. Performance evaluation: An integrated method using data envelopment analysis and fuzzy preference relations. European Journal of Operational Research, in press.

Wu and Olson, 2008 - D. Wu and D. L. Olson, A comparison of stochastic dominance and stochastic DEA for vendor evaluation, International Journal of Production Research 46 (8) (2008), pp. 2313-2327.

Wu et al., $2006 \bullet$ T. Wu, J. Blackhurst and V. Chidambaram, A model for inbound supply risk analysis, Computers in Industry 57 (2006), pp. 350-365.

Xu and Dong, $2004 \bullet \mathrm{K}$. Xu and Y. Dong, Information gaming in demand collaboration and supply chain performance, Journal of Business Logistics 25 (1) (2004), pp. 121-144. 